\title{
Occupational therapy groups as a vehicle to address interpersonal relationship problems: mental health care users' perceptions
}

\author{
Andrea Radnitz, B Occ Therapy (UKZN), M OT (UKZN) https://orcid.org/0000-0002-9760-5537 \\ Occupational Therapist, Akeso, Pietermaritzburg \\ * Chantal Christopher, B OT (UDW), PG Dip in HIV/AIDS Clinical Management, MPhil in Group Therapy \\ (UKZN) https://orcid.org/0000-0002-4959-7288 \\ Lecturer, Discipline of Occupational Therapy, School of Health Sciences, University of KwaZulu-Natal
}

Thavanesi Gurayah, B OT (UKZN), M OT (UKZN) https://orcid.org/0000-000 I-9005-635

Lecturer, Discipline of Occupational Therapy, School of Health Sciences, University of KwaZulu-Natal

Background: This qualitative study set in an acute inpatient psychiatric clinic investigates the efficacy of occupational therapy groups targeting interpersonal relationships, from the clients' perspective.

Purpose: This study was designed to explore the effect of occupational therapy groups on clients' interpersonal relationships.

Method: Four, sixty-minute focus groups were used to ascertain the participants' experiences of groups, and the effect of these on relationships. These sessions were audio-recorded and transcribed. Thematic analysis was used to analyse the data.

Findings: This article tells the story of the development of the participants' relationships through the journey of attending group therapy, from the initial struggles in their personal relationships, through the development of insight into these difficulties, the learning of skills and problem-solving solutions, to the application of some of the skills and hope for future relationship development.

Four emerging themes are discussed in this article. "We all have relationship problems" outlines the participants understanding of their relationship problems. The second theme "we were given the skills and applied them" describes how group therapy helped them develop further insight and acquire greater relational skills. "I am less demanding now" describes how developing insight and skills have impacted the participants' actual relationships and their hopes for their relationships.

Conclusions: Participants gained significant benefit from group work, on both a personal and a relational level. Group therapy provided a safe place to learn and then practice the skills that participants had learnt. The insights gained into adaptive and maladaptive relationships and participants' interpersonal styles through group therapy assisted participants in strengthening their relationships with group members and others. Despite improved knowledge, insight and skills, participants were not always able to use their skills consistently. One factor that improved their confidence to apply skills was consistent group attendance.

Key words: Group Therapy, Acute psychiatry, Interpersonal relationships, practice lessons

\section{INTRODUCTION}

Mental health difficulties are a pervasive and growing issue affecting many people across the globe'. By 2020 unipolar depression alone is predicted to be the second highest contributor to the worldwide burden of disease ${ }^{2}$, while in 2013 , mental and substance use disorders were the leading cause of "years of life lived with disability" worldwide ${ }^{3: 1579}$. These predictions challenge health systems globally, and makes the prevention and treatment of these disorders a priority. Effective and efficient therapy in mental health practice, including occupational therapy practice, is hence important on a national and global level.

Occupational therapy has deep historical roots in mental health care, especially in the treatment of hospitalised mental health care users' (MHCUs) ${ }^{4}$. Group work is one of the core elements of occupational therapy interventions in mental health, and researchers have emphasised the need for further research in this area $^{5-8}$, as there is limited current research to show evidence for practice. In an attempt to contribute to research in this domain, the aim of this study was to explore MHCUs' perceptions of occupational therapy groups as a vehicle to address interpersonal relationship problems.

\section{LITERATURE REVIEW}

\section{The relational difficulties of MHCUs}

Interpersonal relationships play a vital role in fostering mental health ${ }^{9-11}$. Research shows that MHCUs have chronic problems such as poor interpersonal skills, difficulty forming relationships, poor social skills, conflicts with authority, dependency, isolation, inability to express and control anger and hypersensitivity to separation ${ }^{11-14}$. Almost all clients admitted in crisis to an in-patient facility "suffer from a breakdown or absence of supportive relationships with others" $1: 487$. Mental health problems impact on the clients' social relationships and their ability to perform daily activities ${ }^{15}$, making interpersonal relationships an important focus of treatment in acute psychiatric facilities.

\section{The occupational therapist in the treatment of MHCUs}

Occupational therapists play a key role in in-patient care of clients in acute mental health settings, where the four key areas of practice are: individual assessment, therapeutic groups, individual treatment and discharge planning ${ }^{16}$. 
Occupational therapists have expertise and skills which translate into the unique practice of group-work, specifically occupation-focused groups ${ }^{14}$. These groups include activity or 'occupation' such as art, music, movement, role play, and sport, activities of daily living, games and leisure ${ }^{13,17,18}$. Occupational therapists use meaningful activity to provide authentic opportunities for clients to improve life skills and interpersonal relationships ${ }^{14}$

\section{The value of group therapy}

Although there is limited research on occupational therapy group work, there is extensive literature on group therapy from the field of psychology. Group therapy has been shown to have significant benefits to MHCUs ${ }^{11-12,19}$, and is also efficient with the therapists' time, which makes it a vital tool in mental health care.

Duncan 13:266 summarises the value of group therapy when she says: "The group experience is primarily used in occupational therapy to help the client gain more appropriate intra- and interpersonal behaviours".

In a qualitative pilot-study by Cowls and $\mathrm{Hale}^{8,}$ with eight participants in an acute inpatient setting in Canada, the value of occupational therapy groups was explored. All participants indicated that they valued participation and activity. Their participants had a mixed response to skills teaching, with all but one participant finding it valuable. Furthermore, it appeared that participants valued group cohesion and support from other group members, both inside and outside of the groups, and found hearing others' experiences beneficial. Several participants appreciated anger management and assertiveness training and indicated that they wanted more of this in the programme, however, others experienced it as overwhelming.

\section{Study Context}

This study was set in an acute, voluntary, private in-patient psychiatric clinic in KwaZulu-Natal, South Africa, which admits clients with mental health challenges such as mood disorders, post-traumatic stress disorder and anxiety disorders. The combined occupational therapy and psychology treatment plan offers five open groups per week, three of which are occupational therapy groups. Following admission and programme orientation clients join the open groups having been assigned to a specific therapy group by the attending team depending on their needs.

Alongside the group interventions, individual psychotherapy and psychiatric consultations are offered. A three-week programme is provided, while the average length of stay is 14 days.

The occupational therapy groups covered the themes of selfawareness (week one), emotional management (week two), and interpersonal skills (week three). In addition the OT programme, includes life skills groups, craft groups, and relaxation or mindfulness groups. Only the groups relating to week three: "interpersonal skills" are discussed as a part of the study

During the interpersonal relationships' week the psychology programme (average: 9 groups per week) explored topics such as healthy and unhealthy relationships and abusive relationships.

The occupational therapy group programme (average: 16 groups per week) consisted of II groups specifically directed towards interpersonal relationships. The related occupational therapy life skills groups with an interpersonal relationships focus included groups on goal setting, and reflection on client's life roles. These were followed by occupational therapy groups on effective communication such as: understanding communication styles, assertiveness training and conflict management skills, during which role play of these skills are facilitated. The craft groups conducted during the week are topic-related, such as making a greeting card expressing ones' self to a loved one. The occupational therapy groups are concluded with a group called "the way forward," setting relationship goals and making plans to practically apply skills. While the groups build onto each other, each group is able to be understood and benefit the clients independently.

\section{METHODOLOGY}

\section{Design}

A qualitative design was used to explore clients' perceptions of occupational therapy group therapy, as this paradigm is concerned with meaning and lived experiences ${ }^{20}$, and allows for rich, detailed, in depth study ${ }^{21,22}$. The study was underpinned by an interpretivist worldview.

\section{Participants and Sampling}

The psychiatric clinic is divided into two units. Clients from the clinic's general unit, who were admitted for the treatment of mental health disorders, that were not co-morbid with substance abuse, formed the population for this study. The general unit is further divided into clients who are able to participate in reflective and insight-based work, and those that are working on a more concrete level. The clients working on a concrete level were excluded from the study.

Purposive sampling ${ }^{22}$, a non-probability sampling technique, was used to access the participants in the study. This technique is most often used in clinical research to select the most appropriate clients for a study ${ }^{23}$. Twenty-five participants, five males and twenty females between the ages of 18 and 50 years participated in the study, with each one participating in one type of focus group. Clients who had participated in the occupational therapy groups held within the higher functioning, general unit during the week leading up to the focus group, were included in the sample if they had not displayed any psychotic features during this time. Participants had attended on average three groups per day and between five and twenty-two groups during the week.

\section{Data collection}

The data were collected over four months, through a series of four 60-minute focus groups, one after each 'Interpersonal relationships' themed week. Focus groups were used as they are non-threatening, and helpful in obtaining people's perceptions ${ }^{24-26}$. The clients who were invited to participate in the study, were clearly informed of the aims of the study, that their participation was entirely voluntary and their decision not to participate would not impact on their further treatment in any way. To prevent data bias through the ongoing therapeutic relationship with the researcher, the focus group was facilitated by a therapist who had previously worked in the unit. In order to protect confidentiality and ensure anonymity, each participant was given a pseudonym. The focus groups were audio recorded and the facilitator followed a semi-structured interview schedule, which was consistently applied across the focus groups. This included questions such as:

* Before you were admitted what wasn't working in your relationships with others?

* What have you learnt about your relationships this week? What happened that helped you to discover this?

* What has happened in the group that has helped you to understand your relationships outside the group?

* Can you see any changes in yourself and how you are with other people?

* What do you think helped you to change? Did you have any moments in the week that stand out as important?

\section{Data analysis}

Data obtained from the focus group interviews were transcribed by the researcher and audited by the research supervisors. Thematic analysis, using a realist approach, was employed to analyse the data. This approach seeks to report participants' real experiences and their meaning making. Inductive thematic analysis is driven by the data, allowing the data to be grouped into codes and themes without a pre-planned coding matrix ${ }^{27}$.

The aim of data analysis was therefore to clearly understand participants' perceptions of occupational therapy groups that focussed on IPRs by organising the data into themes. After the initial transcription, the data were coded by allocating words or phrases 
that summarised participants' statements. The codes where then studied to identify themes and sub-themes. This allowed the researcher to group and regroup codes to satisfy data representation. These themes were then reviewed, refined and reported ${ }^{27,28}$.

\section{Ethics}

Ethical approval was given by the UKZN Humanities and Social Science Research Ethics Committee (Approval number BE208/I6) as this study was conducted with a vulnerable population. Permission to conduct the study was also obtained from the gatekeepers of the clinic, at both a local and national level. The participant's autonomy and confidentiality were respected through the completion of a detailed consent form (available in either English or isiZulu) in which the aims and procedures of the research were described. This included sections explaining that the focus group would be audio-recorded and a section informing them that they could leave the study at any time with no negative consequences. Respect for the individual participants was upheld by the focus group facilitator and research assistant during the data collection.

\section{FINDINGS}

Four themes, relating to interpersonal relationships, emerged from the data. The first theme, we all have relationship problems, outlines the participants' understanding of their relationship problems, as a baseline for assessing changes. The second theme, we were given the skills and applied them, suggests that occupational therapy groups helped them to develop further insight and acquire greater relational skills within the group. I am less demanding now, describes how developing insight and skills might have impacted on the participants' actual relationships and their hopes for their relationships. Finally, I wish to do that, but it seems impossible, comments on their difficulties and fears in implementing acquired interpersonal skills.

\begin{tabular}{|c|c|}
\hline $\begin{array}{l}\text { We all have } \\
\text { relationship } \\
\text { problems }\end{array}$ & $\begin{array}{l}\text { - Problems based in the participants themselves } \\
\text { - } \quad \text { Problems linked to the participants partners or } \\
\text { family systems } \\
\text { - Stigma of mental illness exacerbates problems }\end{array}$ \\
\hline $\begin{array}{l}\text { So we were } \\
\text { given the skills } \\
\text { and applied } \\
\text { them }\end{array}$ & $\begin{array}{l}\text { - } \quad \text { Benefits of group work on an intrapersonal level } \\
\text { - } \\
\text { - } \quad \text { samily love and support in the groups makes a } \\
\text { Family love and support outside of the group } \\
\text { time } \\
\text { - Groups helped to develop insight and to evaluate } \\
\text { relationships } \\
\text { Shifting from blame to responsibility }\end{array}$ \\
\hline $\begin{array}{l}\text { I am less } \\
\text { demanding }\end{array}$ & $\begin{array}{l}\text { - Direct impact of groups on the participants' } \\
\text { relationships and future plans to impliments } \\
\text { changes }\end{array}$ \\
\hline $\begin{array}{l}\text { But it seems } \\
\text { impossible }\end{array}$ & $\begin{array}{l}\text { - Participants also have some doubts and fears } \\
\text { - The impact of missed groups } \\
\text { The limitations of group therapy }\end{array}$ \\
\hline
\end{tabular}

\section{Figure I: Summary of themes and sub-themes}

\section{Theme I: We all have relationship problems}

The participants shared that they all have relationship problems. They identified the roots of these problems in three different areas. Participants acknowledged problems that were based in their own behaviours, and that other problems were rooted in their intimate partners or families. Other problems were entrenched in the greater family system itself. They expressed that their experience of stigma due to their mental health condition contributed to a large extent to their relationship problems.

\section{I.I Problems based in the participants themselves}

The participants took responsibility for many of the problems in their relationships, including difficulty maintaining relationships, distancing behaviour patterns and poor emotional regulation. These problems correlated with difficulties experienced by other MHCUs in literature, including difficulty forming relationships, anger, and isolation 11,13 .

Menzi shared that he has been generally having difficulties maintaining relationships. Thandiwe spoke about how her distancing behaviour patterns and her demanding behaviour undermined her relationships: I'll keep quiet. I just not even tell you that I'm not fine. Isolate myself. I don't really have friends. She spoke about her demanding behaviour and difficulty respecting boundaries, when she telephones her partner during the night and he doesn't want to speak, she becomes upset and demanding: I will wake him up during midnight, [I] call him...I hate it when he says I'm sleeping. Mpume mentioned her reaction when people do not immediately respond to her messages or phone calls: like come to a conclusion like say: no, you know what, you ignored me, I'm not going to answer your calls, umm you abandoned me and stuff. Through this quote, Mpume displayed how she had been demanding in her relationships and how she makes assumptions of abandonment when others do not respond immediately. She acts on this perceived abandonment with rejection and punishes others without communication or clarification.

Difficulties with emotional regulation were highlighted by Zodwa: I would also be very emotional, and like Nandi, at night I... would even wake up and cry and l'd cry and cry and l'd cry...I would come from work and ... I would just shout, ... at times l'd be very angry, l'd be irritated.

Slowing down of thought processes and diminished ability to think are symptoms of major depression specified in the DSM V ${ }^{29}$. The participants cited difficulties with thinking as having impacted on their conflict management skills. Peter said: [I] sometimes get into an argument with my wife I find it very difficult to think clearly ... so it just gets left.

These descriptions show how the MHCU's symptoms such as insomnia, slowed thought processes and emotional distress along with poor social skills impact negatively on their interpersonal relationships. This finding seems to correlate well with the assertion made by Zlotnick, Kohn and Dela Grotta that "poor intimate relationships are characteristic of a current MDD" "30:205.

Yalom" describes the causality of the MHCU's interpersonal relationship difficulties as being circular in nature, the $\mathrm{MHCU}$ anticipates how others will treat them and then act in a way that causes others to treat them in this way. It seems that the MHCU's maladaptive relationships exacerbated their emotional difficulties, and the emotional difficulties exacerbated their maladaptive relationships, creating a downward spiral.

\section{I.2 Problems linked to the participants' partners or family systems}

Other issues described by the participants related to their partners' behaviours and maladaptive patterns within the family system such as power imbalances, mental illness in the family and poor communication skills in the family as a whole. The participants spoke of how dysfunction in their entire family systems impacted on their interpersonal relationships and their ability to source help.

Participants reported that their families did not offer the emotional support that they desired. Three participants shared that their partners were not invested in the relationship, and that they either shut down communication or changed for a short time before reverting to previous behaviours. This led to a sense of despondency and apathy in the relationships. This was explained by Sné: I thought no, the only thing that I have told him is that I am tired, I just shut up and just see, he has to do as he pleases, that's it. Sné learnt that 
communicating her emotions with her husband was futile. Khanyi shared that her... husband kept this big secret that almost made us go through a divorce. Both Sné and Khanyi's accounts illustrate how some MHCU's endure maladaptive relationships which negatively impact their mental health. This finding correlates well with a study by Nixon, Resick and Nishith ${ }^{31}$ who concluded that high levels of major depressive disorder where found in victims of intimate partner violence.

Power imbalances in the family system contributed to maladaptive relationships. One participant found that the financial power imbalances in the family system prevented family members from confronting her partner's behaviours, in support of her; they rather remained silent out of fear of losing the financial support of her partner.

Communication and conflict management were discussed extensively particularly communication in the family system. Buhle shared how her mother and sister would gossip about her but not talk directly to her. Zodwa highlighted poor communication styles from both passive silences to aggressive screaming: He's the kind of person who just keeps quiet; you can scream, do anything. He will just look at you. Maladaptive family patterns of relating such as punishment, threatening and abandoning behaviours, were cited by participants as contributing to their poor interpersonal relating. These findings concur with the findings of Hammen and Brennan who reported that: "these patterns result not only from maladaptive skills and schemas about the self and others, but also from the life contexts of the depressed women"32:154.

\section{I.3 Stigma of mental illness exacerbates problems}

Participants cited the stigma of having mental health problems as impacting on their relationships. They described both social stigma and internalised stigma, which related to feelings of shame and disempowerment. This resulted in participants attempting to hide their mental health difficulties from others, thus limiting their access to support.

Stigma directed at the participants left them feeling misunderstood, disempowered and rejected. Social stigma has been described in literature as occurring when large groups of people endorse stereotypes of a stigmatised group, and as a result act against this group ${ }^{33}$. Participants interpreted others' negative behaviours towards them as motivated by stigma. Gossip is an example of stigmatising behaviour experienced by the participants in this study. Buhle describes a conflict with her mother and sister who...were gossiping about me not talking to me, so what am I supposed to say? Just because you are crazy, so you have no opinion at home.

Social stigma was implicated in the development of silence surrounding mental health concerns of participants. Sné described how she felt uncomfortable telling others where she was...you can't share with someone else, yet you know your mentality some people took it differently, you see, if you are here, meaning that your mentality is not stable. The social stigma experienced by this participant resulted in her being silent about issues pertaining to her mental health. She wished that the clinic's identity could be hidden or changed so that she ...can be accommodated without...having the stigma of being here. Buhle went on to describe how people have responded to her: Anything and everything I say, 'oooh, don't worry she's crazy'. The experience of these participants is consistent with literature which states that people living with mental illness can feel like they are devalued and discredited by society ${ }^{33}$.

Internalised stigma "can be described as a process whereby affected individuals endorse stereotypes about mental illness, anticipate social rejection, consider stereotypes to be self-relevant, and believe they are devalued members of society" $33: 2154$. The participants did not see themselves as insane, ...l don't see mad people here... and yet they responded to their mental health issues stereotypically. Thandiwe reflected: MyselfI had that stigma... I can never go and be admitted here in a psychiatric hospital... while I am a health worker.

\section{Theme 2: So we were given skills and we applied them}

Participants described significant benefits from group work, on both an intra- and interpersonal level. This was primarily from developing greater insight into their difficulties in relationships and the resultant behavioural change after using the communication and conflict management skills gained in the groups. On an intrapersonal level, participants reported an improved self-esteem and creativity, as well as renewed motivation for participation in their careers with a more positive view of the future. They felt greater levels of personal power and choice while the group space gave them clarity of thought which assisted in problem-solving. A study by Adams and Casteleijn ${ }^{34}$ supports this finding, they emphasise that mutual participation in an occupation can benefit individuals on a personal level, for example, through improved confidence levels.

\section{I Benefits of group work on an intrapersonal level}

Even though the focus of the groups was on development of insight and skills to communicate more effectively in relationships, participants described significant impacts of the group work on themselves on a personal level. Participants reported that the support that they received in the group felt authentic and meaningful. Khanyi gave voice to this sentiment: They are not feeling pity for me and they are not faking it. They mean what they are doing and are really supporting. The participants asserted that this was what gave them hope and helped reduce their symptoms quickly. Mpume echoed this sentiment: Group work actually had a huge effect on me and actually I felt supported.... These comments support literature that states the emotional support that clients receive in the initial stages of group therapy is the most important aspect of therapy ${ }^{8}$. A significant benefit of group therapy over individual therapy was that of "universality", and "instillation of hope", as described by Yalom and Leszcz" I:I. Buhle: ...I realise I am not alone. It gives me that hope. Buhle experienced the power of universality and developed hope, helping her to feel better.

\subsection{Family love and support inside groups makes space to practice skills}

Participants shared experiences of love and support within the groups, even referring to the group as a family. This finding is supported by Yalom and Leszcz who describe the therapy group as a recapitulation of the primary family group ". Buhle gives voice to this feeling: this is your family, [only] better, from home. Buhle compares the group to her biological family at home and finds the groups' support is better than that which she receives at home. She goes on to say: it's not like with your psychologist...these people they'll tell you something they went through, emphasising that participants found the authenticity of other group members sharing or offering support from their own life experiences as beneficial. Mpume, despite being fairly new to the group said: I felt loved, support, hence I didn't know most of the people that well, I'm still new here. But it was so warm, I felt like it was my family I felt when I was taken care of. Their descriptions of the group space were reflective of Yalom's therapeutic factors, particularly: "universality and the corrective recapitulation of the primary family group, catharsis, and group cohesiveness" "I:I. Participants related an incident in which a participant became angry during a group and left. Later the group was able to discuss and resolve the conflict. In reflecting on this process Khanyi shared: But I must say guys, I am proud of the way in which we handled the conflict we had within the family... so we were given skills and we applied them. The group is a useful place to learn conflict management skills, to apply them in the here and now with a multifaceted positive outcome, which included feelings of pride, the experience of success, improved group cohesion and conflict management skills. This outcome corresponds to the findings described by Cowls and Hale that clients appreciated the connection with other group members and valued activity based life skills groups ${ }^{8}$. 


\subsection{Family love and support outside of group therapy time}

Member subgrouping, and contact between group members outside of group time is discouraged by Yalom and Leszcz " as the problems of extra-group relationships are complex. In the South African context, support groups post-discharge are rare, and often difficult to access. Musa shared how much they valued the time spent with each other after groups: To work as a team, even outside, even outside there on the breaks we are talking to each other. Buhle disclosed: we formed a WhatsApp group..., you know people there, they are still talking they are still saying their problems and we try to help each other. Mandla spoke of a supportive relationship he had developed and shared: we will keep in touch to check me up, if I am doing right, guiding me. Although Yalom and Leszcz say this does complicate the group dynamics, they add that in some groups extra-group activities have been beneficial" .

\subsection{Groups helped to develop insight and evaluate re- lationships}

The participants described how groups have helped them to evaluate and develop insight into their relationships and their patterns of relating. Zodwa is a testament of this, prior to her participation in occupational therapy groups she was unaware of her relational problems: I didn't realise that I was having problems per se, I just thought that I was being me. Post occupational therapy intervention, she had gained insight into her problems with interpersonal relating and gained a deeper understanding of the mechanics and components of communication, including perspective taking, choosing the appropriate time and place for communication, emotional control and de-escalation of heightened emotional arousal. Zanele shared the importance of learning about healthy and unhealthy relationships: ...how is a healthy relationship supposed to be and most importantly communication styles...you might think that I am approaching you in a good manner but it's actually not a good manner and being assertive... could assist me like in rebuilding or reconstructing my relationships. Grant alternatively learnt about aspects of communication: I know now how to communicate properly. (Ex)Cept, you know, not having that attitude or not having that certain body language that shows that I have got an attitude. I know which tone of voice to use (said with a closed body posture). Participants reflected that they had gained much knowledge on how to communicate more effectively and understood the mechanics of communication. However, Grant illustrated that it was a learning process and that knowing about communication and practicing the skills does not necessarily mean that participants will consistently be able to apply what they have learnt.

\subsection{Shifting from blame to responsibility}

A noteworthy change in the participants was a shift from blaming others for problems, to taking a greater level of responsibility for their own contributions to the relational difficulties. This is reflected in Sarah's quote: I am sorry for the hurt that I have caused him, and I see now that most of the arguments that did happen was because of my tantrums...instead of blaming him; it's you, it's you, it's you' I took blame this time. It appears that Sarah gained insight, through groups, into her contribution to their relational difficulties and gained a more balanced view of the relationship. The insights gained in group therapy were then developed into changes in behaviour and relationships described in the third theme.

\section{Theme 3: I am less demanding now}

This theme describes perceived changes in the participants interpersonal relating, as a result of occupational therapy groups and their intentions to maintain the changes that they have made in their lives post-discharge.

Participants felt that they were less demanding, more trusting and able to recognise the needs of others more easily. Londi shared: l've learnt trust, to trust people that are around me. They reflected that they had stopped isolating themselves and were socialising more with the other group members as well as their families, as reflected in Bandile's quote: The change I've noticed, now I can sit with my family around the table have a nice chat, and with my friends. Janet used assertive communication skills with her mother: she was very understanding... it has brought my mom and I a little bit closer together than before. Bandile reinforced this when he said: I am speaking out and telling them how I feel. Now I can see their response... changing is giving me that comfort that I needed before. Both Janet and Bandile demonstrated that as they started changing the way they communicated in their relationships, their families' response and the actual relationship itself improved.

Occupational therapy groups seem to have assisted participants to establish boundaries in their relationships. Wandile, initially ... not a confronting person, went on to describe how she had been able to confront her cheating partner and tell him that she was ending the relationship. Khanyi summarised these changes: I just found a calmer way of talking to him. Like I feel, like he may be pleased with this type, I am less demanding now. I'm less possessive now; I do recognise his needs now. I used to put my needs before his. I learned that he make mistakes and I think there is still hope for us now. The findings of this study seem to correlate with literature that shows that intensive group psychotherapy programmes can improve interpersonal functioning ${ }^{11,35}$.

Not only did participants feel that they were currently less demanding, but they had also developed plans for taking this into their relationships in the future. Participants planned to bring a healthier self to these relationships, to improve their communication with others, and to continue to apply the skills they had learnt. Fikile spoke about her desire to be assertive at work: That I am allowed to have problems, and I have got leave and I am allowed leave, so please stop talking behind my back, if you have a problem with me please address it.

\section{Theme 4: I wish I could do that but it seems impossible}

Although it appears that group therapy gave hope to participants for their future relationships, three participants held doubts and insecurities about applying these skills. One participant wondered if the theory would be effective in practice. Another expressed doubt that they would not know what to do if people responded badly to their attempts to communicate.

Noteworthy is the impact of missed groups on the participants' confidence in applying their skills. In contrast to Fikile who attended a group on assertiveness and felt confident in using her skills, Buhle, who had missed the assertiveness group, commented, I wish to do that, but it seems impossible at my work.

Moreover, some participants expressed confidence in engaging with assertiveness training and applying these skills, whilst others had difficulty transferring these skills as they were unable to be assertive with the exercise instructor. This can be seen in Buhle's quote: they are afraid to ask him to lower the tone.

The participants were also aware that one of the limitations of group therapy is that it cannot change the outside world, and some of them faced the challenge of returning to maladaptive or abusive relationships. This could have evoked one of the three forms of isolation that Yalom identified, namely interpersonal isolation, intrapersonal isolation or existential isolation ${ }^{36}$. Systemic problems are not solved by treating the individual, however. Fikile speaks to this problem when she describes the power of choice that victims of abuse have: yes, you have a choice, you can say: 'I didn't have a choice ...I stayed until you beat me up and I lost my leg'. No, you had a choice you have to accept that I am being beaten up or exit. Although group therapy does not treat the whole family system, some participants left feeling empowered to change the system, and others found that as they changed their behaviour, the system also changed.

\section{DISCUSSION OF FINDINGS}

Participants described the main problems they experienced in interpersonal relationships, with many of the participants enduring long-term maladaptive relationships. A downward spiral seemed 
to develop through the interplay between mental health disorder symptoms, such as poor emotional regulation, and deteriorating relationships. The stigma of being diagnosed with a mental health disorder appeared to aggravate this spiral. The impact of stigma on people with mental illness is well documented in literature ${ }^{33}$, however, the large significance of stigma on participants' relationships was an unanticipated sub-theme of the data, and highlights the need to address this more directly within the group therapy programme.

During group therapy, this downward cycle appeared to start to reverse, as the participant received acceptance, authentic support, and social connection. This seem to have provided a safe space to practice social skills and as a result strengthen self-esteem and positive relationships, leading to a greater level of acceptance and mental health. The group members indicated that their skills improved within the supportive environment of the group, and that they gained the confidence to apply skills in their personal relationships, setting firmer boundaries in some relationships and deepening connections within others. Although participants have learnt the theory of communication and had some opportunity to practice, they were not all able to apply all skills. Continued opportunities to practice and apply skills need to be regularly offered in the group programme. Missed groups seem to have an impact on the participants' skills, even though it was inevitable that groups would be missed due to individual consultations with doctors and psychologists, physical illness and the need for further testing or scans. Improved communication within the multi-disciplinary team and better scheduling of appointments may assist in reducing the number of groups being missed.

Although group therapy does not directly change unhealthy systems, the group members reported that they felt empowered and able to accept the system, change their part of the system, or leave the system. This finding speaks to the fragmentation of the South African health care system, particularly the poor post discharge care and family intervention. Although the participants described changes, growth and empowerment, they were also aware that they had started a journey which could not be completed during an acute admission. Buhle gives voice to this: for me, I can say it's a long, long, long road to walk; I still need to walk, because I only just discovered myself. Buhle's long road cannot be addressed during an acute hospital stay and there is an ethical requirement to create opportunities for those without transport or finance to access further health care. This access will promote social and emotional support and foster the maintenance of skills learnt. Research into the long-term outcomes of this type of contact would be valuable. These points give further clarity to the following section, implications for practice.

\section{Implications for practice}

Group therapy in South African public and private institutions have been influenced by context, particularly in terms of the length of stay, the cost implications as approved by the medical aid, as well as the composition and purview of the multidisciplinary team. This study demonstrates that the creation of a supportive group environment with a strong focus on applying skills consistently is the gold standard of care. That being said, therapy should address systemic issues that foster, create or exacerbate mental health conditions. These deep and intersecting issues are often addressed in family therapy and post discharge. This study therefore encourages occupational therapists to lobby for outpatient groups and family therapy.

\section{Limitations of the study and recommendations for further research}

The limitations of the study relate to this being a small study focusing on the content of one week of the programme and limited to one site. Another limitation of the study is that the clients were exposed to psychotherapy groups during the same time frame, and the effect of these groups could not be separated from the effects of the occupational therapy groups. Further research is needed in this area to gain a clearer understanding of what is best practice for occupational therapists working with MHCUs with very limited contact time, to make the greatest impact on their clients' lives. This should include larger studies at multiple sites, and long term studies, noting if the impact of group therapy is sustained.

\section{CONCLUSION}

In the South African context of social and economic stress there are many people struggling with mental health diseases and who have limited resources to meet these needs, and occupational group therapy has been perceived by the participants as having had an impact in people's lives, assisting them on a journey to recovery and improved interpersonal relating. The outcomes of this study are congruent with the finding of the 2005 study by Cowls and $\mathrm{Hale}^{8}$ in that participants value and benefit from assertiveness skills learnt through activity, they also really value support and group cohesion in the group.

\section{REFERENCES}

I. Kessler RC, Aguilar-Gaxiola S, Alonso J, Chatterji S, Lee S, Orme J, et al. The global burden of mental disorders: An update from the WHO World Mental Health (WMH) Surveys. Epidemiologia e Psichiatria Sociale, 20 I I Apr II; I8(I):23-33.

2. Murray CJL, Lopez AD. Alternative projections of mortality and disability by cause 1990-2020: Global Burden of Disease Study. Lancet, 1997;349:|498-504.

3. Whiteford HA, Degenhardt L, Rehm J, Baxter AJ, Ferrari AJ, Erskine $\mathrm{HE}$, et al. Global burden of disease attributable to mental and substance use disorders: findings from the Global Burden of Disease Study 2010. Lancet, 2013 Nov 9;382(9904): I575-86. https://doi.org/10.1016/S0140-6736(13)6161 I-6.

4. Patterson CF. A short history of occupational therapy in psychiatry In: Creek J, Lougher L, editors. Occupational Therapy and Mental Health. 4th ed. Philadelphia: Churchill Livingstone Elsevier, 2008: 3-14. (2015, Nov 28)

5. Gutman SA, Raphael-Greenfield El. Five years of mental health research in the American Journal of Occupational Therapy, 2009-2013. American Journal of Occupational Therapy, 2014 Jan; 68(I ):e2 I-36. https://doi.org/10.5014/ajot.2014.010249.

6. Haertl K, Behrens K, Houtujec J, Rue A, Ten Haken R. Factors influencing satisfaction and efficacy of services at a free-standing psychiatric occupational therapy clinic. American Journal of Occupational Therapy, 2009; 63(6): 69l-700. https://doi.org/10.5014/ajot.63.6.69l

7. Rebeiro KL. Occupation-as-Means to Mental Health: A Review of the Literature, and a Call for Research. Canadian Journal of Occupational Therapy, 1998 Feb I;65(I): 12-9.

8. Cowls J, Hale S. It's the activity that counts:What clients value in psycho-educational groups. Canadian Journal of Occupational Therapy, 2005; 72:176-82. https://doi.org/10.I I77/00084I 740507200305.

9. Dozier M, Stovall KC, Albus KE. Attachment and Psychopathology in adulthood. In: Cassidy J, Shaver PR, editors. Handbook of Attachment: Theory, Research, and Clinical Applications. New York: Rough Guides; 1999: 497-5I0 (2015, Dec I2)

10. Baron RA, Branscombe NR, Byrne D. Social Psychology. I2th ed. Boston: Pearson International; 2009.

II. Yalom ID, Leszcz M. The Theory and Practice of Group Psychotherapy. $5^{\text {th }}$ ed. New York: Basic Books; 2005, 668p.

12. Yalom ID. Inpatient Group Psychotherapy. New York: Basic Books; 1983: 416.

13. Duncan M. Occupational therapy with anxiety and somatoform disorders. In: Crouch RB, Alers VM, editors. Occupational Therapy in Psychiatry and Mental Health. 3rd ed. Cape Town: Maskew Miller Longman; 1997. Ch 23, 247-7I. https://doi.org/10.1002/9781 | 189/3536.

14. Occupational Therapy Association of South Africa. Position statement on theraputic group work in Occupational Therapy. South African Journal of Occupational Therapy, 20I4; 44(3): 43-44.

15. Buist-Bouwman MA, De Graaf R, Vollebergh WAM, Alonso ], Bruffaerts R, Ormel J. Functional disability of mental disorders and comparison with physical disorders: a study among the general 
population of six European countries. Acta Psychiatrica Scandinavica, 2006; I I3(6):492-500. http://dx.doi.org/I0. I I I I/j. I600-0447.2005.00684.x

16. Lloyd C, Williams PL. Occupational therapy in the modern adult acute mental health setting:a Review of Current Practice. International Journal of Therapy and Rehabilitation, 20I0; I7(9):436-42.

17. van Greunen A. Occupational therapy with mood disoders. In: Crouch R, Alers VM, editors. Occupational therapy in Psychiatry and Mental Health. 3rd ed. Cape Town: Maskew Miller Longman. 1997: 273-82.

18. Nott A. Understanding persons with personality disorders: intervention in occuaptional therapy. In: Crouch R, Alers VM, editors. Occupational Therapy in Psychiatry and Mental Health. 5th ed. John Wiley and Sons, 2014.

19. Corey G, Corey C, Corey MS. Groups: Process and Practice. 8th ed. Belmont: Brooks/Cole Cengage learning; 2008.

20. Willig C. Introducing Qualitative Research In Psychology. 3rd ed. Maidenhead: McGraw-Hill Education (UK); 20I3: 250.

21. Patton MQ. Qualitative Research and Evaluation methods. 3rd ed. Thousand Oaks: Sage Publications, 2002. https://doi.org//0.12691/education-3-10-6.

22. Mack N, Woodsong K, MacQueen K, Namey E, Guest G. Qualitative Research Methods: A data collector's field guide. Research Tridangle park: Family Health International, 2005: I-I 20.

23. Acharya AS, Prakash A, Saxena P, Nigam A. Sampling: why and how of it? Indian Journal of Medical Specialities, 2013 Jul 7;4(2):330-3. https://doi.org//0.77/3/ijms.2013.0032.

24. Krueger RA, Casey MA. Focus Groups: A Practical Guide for Applied Research. $5^{\text {th }}$ ed. New Delhi: SAGE Publications, 2014: 280.

25. Marczak M, Sewell M. "Using focus groups for evaluation" [Internet]. The University of Arizona, Tucson Arizona. 2013. p. I-8. Available from: http://ag.arizona.edu/sfcs/cyfernet/cyfar/focus.htm (20I5 Nov 2I).

26. Ogunbameru O. Focus Groups : Issues and Approaches. The Anthropologist, 2003; 5 (I) p. I-8. [cited 2015 Nov 2I]. https://doi.org/I0.1080/09720073.2003.II89077I.

27. Braun V, Clarke, V. Using thematic analysis in psychology. Qualitative Research in Psychology, 2006; 3(2), 77- I0I. [Accessed 30 September 2017.

http://tandfonline.com/doi.abs/10.1 191/1478088706qp0630a.

28. Saldana J. The Coding Manual for Qualitative Researchers. SAGE Publications; 2015: 187-242.
29. American Psychiatric Association: Diagnostic and Statistical Manual of Mental Disorders. $5^{\text {th }}$ ed. Arlington,VA: American Psychiatric Association; 2013.

https://doi.org/I0.I I 76/appi.books.9780890425596.

30. Zlotnick C, Kohn R, Keitner G. The relationship between quality of interpersonal relationships and major depressive disorder: findings from the National Comorbidity Survey. Journal of Affective Disorders, 2000; 59(3): 205-2I5.

31. Nixon RDV, Resick PA, Nishith P. An exploration of comorbid depression among female victims of intimate partner violence with posttraumatic stress disorder. Journal of Affective Disorders, 2004 Oct I5; 82(2): 315-320. https://doi.org/doi:10.1016/j.jad.2004.01.008.

32. Hammen C, Brennan PA. Interpersonal dysfunction in depressed women: impairments independent of depressive symptoms. Journal of Affective Disorders, 2002 Nov I; 72(2): |45-56.

33. Livingston JD, Boyd JE. Correlates and consequences of internalized stigma for people living with mental illness: A systematic review and meta-analysis. Social Science and Medicine, 20 I 0;7I(I2):2I50-6I. https://doi.org/10.1016/j.socscimed.2010.09.030.

34. Adams F, Casteleijn D. New insights in collective participation : A South African perspective. South African Journal of Occupational therapy, 20I4; 44(I): 8I-87.

35. Kinley JL, Reyno SM. Attachment Style Changes Following Intensive Short-term Group Psychotherapy. International Journal of Group Psychotherapy: 2013; 63(I):53-75. https://doi.org/10.1521/iigp.2013.63.1.53.

36. Yalom, ID. Existential Psychotherapy. New York, NY: Basic Books; 1980. 